\title{
Ion-Beam Formation and Track Modification of InAs Nanoclusters in Silicon and Silica
}

\author{
F. F. Komarova , O. V. Milchanin ${ }^{a}$, V. A. Skuratov $b$, M. A. Makhavikou ${ }^{a}$, A. Janse van Vuuren ${ }^{c}$, \\ J. N. Neethling ${ }^{c}$, E. Wendler ${ }^{d}$, L. A. Vlasukova ${ }^{e}$, I. N. Parkhomenko ${ }^{e}$, and V. N. Yuvchenko ${ }^{a}$ \\ ${ }^{a}$ Sevchenko Institute of Applied Physical Problems, Belarusian State University, Minsk, 220030 Belarus \\ ${ }^{b}$ Joint Institute for Nuclear Research, Dubna, 141980 Russia \\ ${ }^{c}$ Centre for High Resolution Transmission Electron Microscopy, Nelson Mandela Metropolitan University, \\ Port Elizabeth, 6031 South Africa \\ ${ }^{d}$ Friedrich Schiller University Jena, 07743 Jena, Germany \\ ${ }^{e}$ Belarusian State University, Minsk, 220030 Belarus \\ e-mail: komarovf@bsu.by
}

\begin{abstract}
The implantation formation of InAs nanoclusters in silicon and silica and their modification via irradiation with Xe ions with an energy of $167 \mathrm{MeV}$ and a fluence of $3 \times 10^{14} \mathrm{~cm}^{-2}$ are studied. It is found that post-implantation annealing and irradiation with high-energy ions alter the size and shape of nanoclusters and cause structural transformations within them. The ordering of nanoclusters and their elongation along the trajectory of $\mathrm{Xe}$ ions in a $\mathrm{SiO}_{2}$ matrix is observed.
\end{abstract}

DOI: $10.3103 / \mathrm{S} 106287381602012 \mathrm{X}$

\section{INTRODUCTION}

The fabrication of composite microelectronics and photonics systems based on silicon and the replacing of electronic switching in highly integrated silicon systems with optic switching have been given much attention in recent years. Silicon is an indirect-gap semiconductor and is not a proper material for these purposes. A number of works published by the authors of the present study [1-3] and other research groups [4] focused on studying the formation of nanocrystals of direct-gap $\mathrm{A}^{3} \mathrm{~B}^{5}$ semiconductors (including narrowbandgap semiconductors InAs, InSb, and $\mathrm{GaSb}$ ) via the oversaturation of silicon with impurities of groups III and V of the periodic system and subsequent thermal treatment (long-term equilibrium or rapid). Intense photoluminescence in the near IR range $(0.75-1.10 \mathrm{eV})$ was observed for $\mathrm{A}^{3} \mathrm{~B}^{5}$ nanoclusters in silicon. Clarification of the mechanisms of this luminescence and the search for methods to synthesize nanocrystals with a narrow size distribution are both important objectives. Irradiation with ions of moderate and high energies allows us to vary selectively the sizes of formed nanoclusters [5].

In this work, InAs nanoclusters were synthesized in $\mathrm{Si}$ or $\mathrm{SiO}_{2}$ via high-dose ion implantation with subsequent thermal treatment and/or irradiation with highenergy xenon ions.

\section{EXPERIMENTAL}

Wafers of $n$-Si (100) with thermal $\mathrm{SiO}_{2}$ and thicknesses of 40 or $600 \mathrm{~nm}$ were irradiated first with $\mathrm{As}^{+}$ ions $\left(170 \mathrm{keV}, 3.2 \times 10^{16} \mathrm{~cm}^{-2}\right)$ and then with $\mathrm{In}^{+}$ions $\left(250 \mathrm{keV}, 2.8 \times 10^{16} \mathrm{~cm}^{-2}\right)$. The $\mathrm{SiO}_{2}(40 \mathrm{~nm}) / \mathrm{Si}$ system was irradiated at $T=550^{\circ} \mathrm{C}$, while the $\mathrm{SiO}_{2}$ $(600 \mathrm{~nm}) / \mathrm{Si}$ system was irradiated at $T=300 \mathrm{~K}$. A number of the samples were then annealed at $900^{\circ} \mathrm{C}$ in argon for $45 \mathrm{~min}\left(\mathrm{SiO}_{2}(40 \mathrm{~nm}) / \mathrm{Si}\right)$ or $30 \mathrm{~min}\left(\mathrm{SiO}_{2}\right.$ $(600 \mathrm{~nm}) / \mathrm{Si})$ to let InAs nanoclusters precipitate. Some annealed and some nontreated samples were then irradiated with high-energy $\mathrm{Xe}^{+}$ions $(167 \mathrm{MeV}$, $3 \times 10^{14} \mathrm{~cm}^{-2}$ ) at room temperature. Transmission electron microscopy (TEM and XTEM) and Raman scattering (RS) were used to characterize the structural and optical properties of the systems under study.

\section{RESULTS AND DISCUSSION}

The thermal fields in $\mathrm{SiO}_{2}$ were calculated and the radii and lifetimes of molten regions left by Xe ions were estimated using the thermal spike model [6] in order to characterize the structure and phase transformations in $\mathrm{SiO}_{2}$ irradiated with fast Xe ions. It follows from our calculations that the radius of a molten region was $6 \mathrm{~nm}$, and its lifetime was $23.8 \mathrm{ps}$.

In order to discuss the effect of fast Xe ions on InAs nanoclusters in $\mathrm{SiO}_{2}$, we must also estimate the maximum size of nanoclusters that would melt upon irradi- 


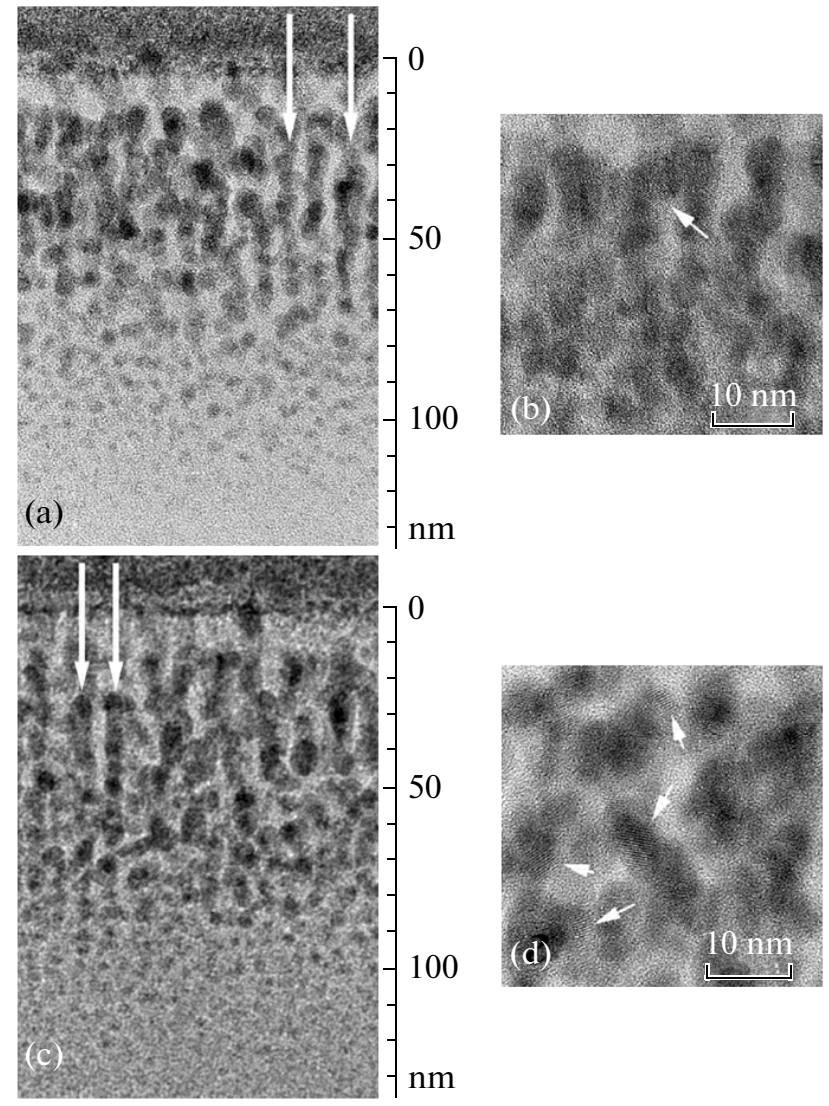

Fig. 1. XTEM images of the $\mathrm{SiO}_{2}(600 \mathrm{~nm}) / \mathrm{Si}$ structures irradiated with $\mathrm{Xe}$ ions $(\mathrm{a}-\mathrm{d})$ after implantation of As $\left(170 \mathrm{keV}, 3.2 \times 10^{16} \mathrm{~cm}^{-2}\right)$ and In $\left(250 \mathrm{keV}, 2.8 \times 10^{16} \mathrm{~cm}^{-2}\right)$ ions at $550^{\circ} \mathrm{C}$ and subsequent annealing (c, d) at $900^{\circ} \mathrm{C}$ for 45 min. (b, d) XTEM images in high-resolution mode.

ation with Xe ions with energies of $167 \mathrm{MeV}$. The following expression [7] is used for this purpose in the literature:

$$
R_{N P}^{\max }=\sqrt{\frac{3(d E / d x)_{e, N P}}{2 \pi H_{N P}^{m} \rho_{N P}}},
$$

where $(d E / d x)_{e, N P}$ denotes the specific ion losses for electron excitations in a nanoparticle, $\rho_{N P}$ is the density of material in this particle, and $H_{N P}^{m}$ is the heat of melting. In our view, the result is more accurate if the energy that goes into heating a nanoparticle to the melting temperature is also taken into account:

$$
R_{N P}^{\max }=\sqrt{\frac{3(d E / d x)_{e, N P}}{2 \pi\left(H_{N P}^{m} \rho_{N P}+Q\right)},},
$$

where $Q($ InAs $)=\rho_{N P} C\left(T_{m}-T_{i r r}\right)=1820 \mathrm{~J} \mathrm{~cm}^{-3}, C$ is the specific thermal capacity, $T_{\mathrm{m}}$ is the melting temperature, and $T_{\text {irr }}$ is the sample temperature during irradiation.
The following result is obtained after the characteristics of InAs nanoclusters $\left(\rho_{N P}=5.67 \mathrm{~g} \mathrm{~cm}^{-3}\right.$ and $\left.H_{N P}^{m}=503 \mathrm{~J} \mathrm{~g}^{-1}\right)$ and the value $(d E / d x)_{e, N P}=$ $19.2 \mathrm{keV} \mathrm{nm}^{-1}$ (SRIM 2015) are inserted into formulas (1) and (2): $R_{N P}^{\max }=22.8 \mathrm{~nm}$ (1) or $17.8 \mathrm{~nm}$ (2).

It is known from experiments that the irradiation of single-crystalline silicon with fast individual (noncluster) ions of any type does not allow detection of track regions [8], due to the rapid epitaxial crystallization of molten regions around the trajectories of ions in silicon.

Figure 1 shows the XTEM images of the silica layers that were irradiated with $\mathrm{Xe}^{+}$ions immediately after the implantation of indium and arsenic (Fig. 1a) or following the implantation and thermal treatment (Fig. 1c). It can be seen that the structures of silica with nanoclusters are similar. Clusters are observed at depths of $0-120 \mathrm{~nm}$. There are two distinct layers: one with larger clusters $(5-8 \mathrm{~nm})$ at depths of $0-70 \mathrm{~nm}$ and another with small clusters $(2-4 \mathrm{~nm})$ at depths of $70-120 \mathrm{~nm}$. The near-surface layer $10-15 \mathrm{~nm}$ thick in both samples contains almost no clusters. The precipitates are round, although some of them (found in the upper layer at $0-70 \mathrm{~nm}$ ) are oval (elongated along the direction perpendicular to the sample surface). Small clusters in the lower layer at $70-120 \mathrm{~nm}$ are almost round. Irradiation with $\mathrm{Xe}$ ions produces extended regions of cluster overlap (merger) with lengths of up to $50-60 \mathrm{~nm}$ that are indicated with arrows in Fig. 1.

Irradiation with Xe ions also results in the fragmentation of large InAs clusters into smaller ones with sizes of $6-8 \mathrm{~nm}$. Considering the abovementioned size of track (molten) $\mathrm{SiO}_{2}$ regions, a 339-fold overlap of tracks is observed at a xenon fluence of $3 \times 10^{14} \mathrm{~cm}^{-2}$. The resulting size distribution of nanoclusters thus depends only weakly on their size distribution prior to irradiation. Figures 1b, 1d show detailed high-resolution TEM images of InAs clusters synthesized in silica. Predominantly amorphous precipitates are found in the sample irradiated with Xe ions immediately after the implantation of indium and arsenic ions.

Only a small fraction (several percent) of these precipitates in the near-surface region are crystalline. One is marked with an arrow in Fig. 1b. The interplanar distances in such precipitates were calculated using TEM data and were found to be $0.348 \pm 0.005 \mathrm{~nm}$. This value agrees with the tabular data for $\{111\}$ planes of crystalline InAs $(0.3489 \mathrm{~nm})$. Crystalline precipitates (marked with arrows in Fig. 1d) are also observed in the silica sample irradiated with Xe ions after the implantation of $\mathrm{As}^{+}$and $\mathrm{In}^{+}$and thermal treatment, and they occur in much greater numbers: more than $60 \%$ of the clusters are estimated to be crystalline. It can also be seen from Fig. 1 that clusters (both crystalline and amorphous) are elongated primarily in the 
(vertical) direction perpendicular to the surface. The regions of merger of clusters along this direction are also seen.

Figure 2 shows typical XTEM images of high resolution mode of $\mathrm{SiO}_{2}(40 \mathrm{~nm}) / \mathrm{Si}$ structures irradiated with xenon after the hot implantation of indium and arsenic ions or after implantation and annealing. The thickness of the defect layer in crystalline silicon irradiated with Xe ions following cluster-forming implantation is $\sim 240 \mathrm{~nm}$ (Fig. 2a). This value is much higher than the one in silica $(120 \mathrm{~nm})$; an elevated implantation temperature $\left(550^{\circ} \mathrm{C}\right)$ thus results in more active diffusion of indium and arsenic atoms in single-crystalline silicon during implantation.

This disordered layer remains crystalline, but it contains defect clusters and small microtwins. The formation of crystalline InAs precipitates (marked with arrows in Fig. 2a) with moire fringes on them was also detected. These precipitates with sizes of up to $20 \mathrm{~nm}$ are localized at depths of $0-100 \mathrm{~nm}$. Irradiation with fast ions results in notable recovery of the crystalline structure of silicon in samples irradiated both immediately after the implantation of indium and arsenic ions and after implantation and thermal treatment (Fig. 2b). Secondary structure defects (primarily small dislocations) are observed at a depth of $240 \mathrm{~nm}$. The entire silicon layer has a crystalline structure with implanted InAs crystals. A considerable fraction of these crystals have sizes up to $50 \mathrm{~nm}$ (arrows 1 in Fig. 2b). However, small (2-5 nm) InAs crystals (arrows 2 in Fig. 2b) are also found in the near-surface layer at depths down to $\sim 200 \mathrm{~nm}$.

The RS technique was used to identify precipitates in $\mathrm{Si}$ and $\mathrm{SiO}_{2}$ after thermal treatment and irradiation with Xe ions. It is known that RS bands with maxima at 217.3 and $238.6 \mathrm{~cm}^{-1}$ correspond to transverse (TO) and longitudinal (LO) optical phonons of the crystalline InAs phase [9]. The positions of maxima can vary, depending on the nanocrystal size and the presence of stresses.

Figure 3 shows the RS spectra of $\mathrm{SiO}_{2}(40 \mathrm{~nm}) / \mathrm{Si}$ and $\mathrm{SiO}_{2}(600 \mathrm{~nm}) / \mathrm{Si}$ samples implanted with $\mathrm{In}$ and As ions before and after thermal treatment. A weak band in the region of optical phonons of crystalline InAs is seen in the RS spectrum for the as-implanted $\mathrm{SiO}_{2}$ film. The TEM data reveal that InAs nanocrystals formed both in the as-implanted $\mathrm{SiO}_{2}(600 \mathrm{~nm}) / \mathrm{Si}$ sample and in the $\mathrm{SiO}_{2}(40 \mathrm{~nm}) / \mathrm{Si}$ sample. The lack of an RS signal from the crystalline InAs phase in the asimplanted $\mathrm{SiO}_{2}(40 \mathrm{~nm}) / \mathrm{Si}$ sample can be attributed to the depth of penetration of the excitation radiation $(473 \mathrm{~nm})$ which is less than the one in the $\mathrm{SiO}_{2}$ $(600 \mathrm{~nm}) /$ Si sample.

After thermal treatment, the signal from the crystalline InAs phase was detected both for $\mathrm{SiO}_{2}$ $(600 \mathrm{~nm}) / \mathrm{Si}$ and $\mathrm{SiO}_{2}(40 \mathrm{~nm}) / \mathrm{Si}$. The increase of (a)

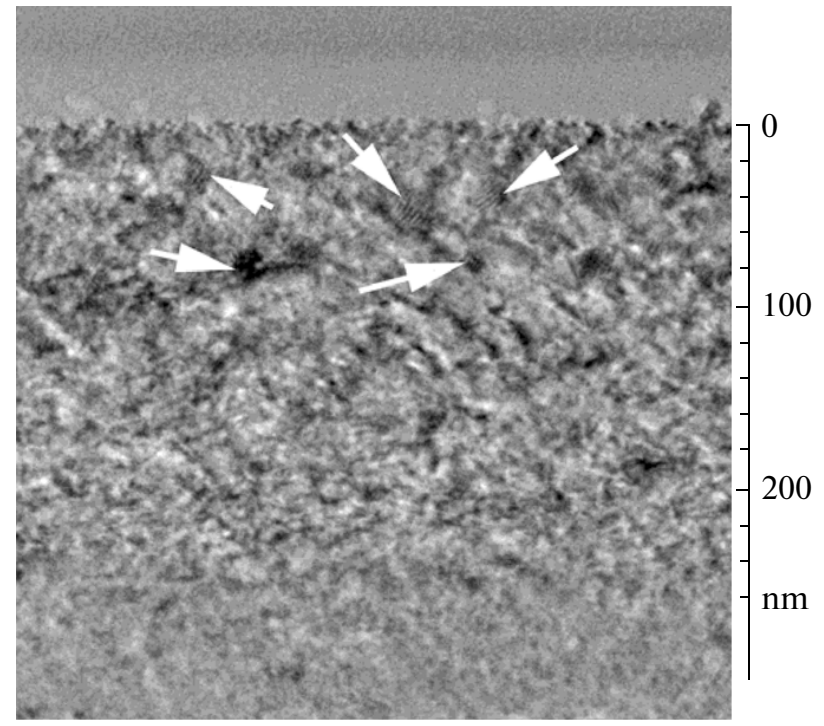

(b)

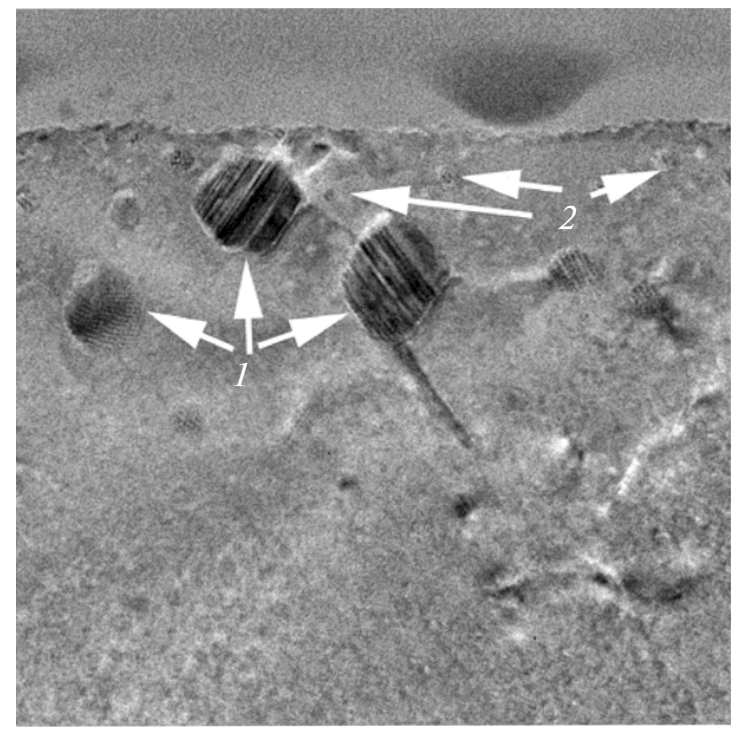

Fig. 2. XTEM images in high resolution mode of the $\mathrm{SiO}_{2}(40 \mathrm{~nm}) / \mathrm{Si}$ structures after (a) the implantation of As $\left(170 \mathrm{keV}, 3.2 \times 10^{16} \mathrm{~cm}^{-2}\right)$ and In $\left(250 \mathrm{keV}, 2.8 \times 10^{16} \mathrm{~cm}^{-2}\right)$ ions at a temperature of $550^{\circ} \mathrm{C}$, (b) subsequent annealing at $900^{\circ} \mathrm{C}$ for $45 \mathrm{~min}$, and $(\mathrm{a}, \mathrm{b})$ irradiation with Xe ions.

intensity after annealing could be associated with an increase in the number of crystalline InAs clusters, their growth in size, and the recovery of the structure of the surrounding matrix during thermal treatment. It is worth mentioning that the maximum of the TO phonon band upon the implantation of cluster-forming ions into silica is found at higher frequencies than the maximum in the implanted and annealed $\mathrm{SiO}_{2}$ 
(a)

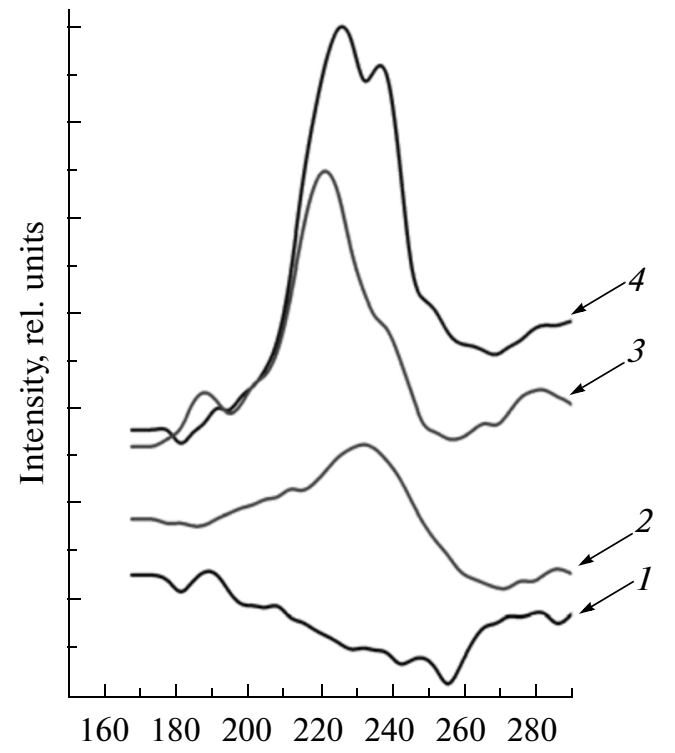

(b)

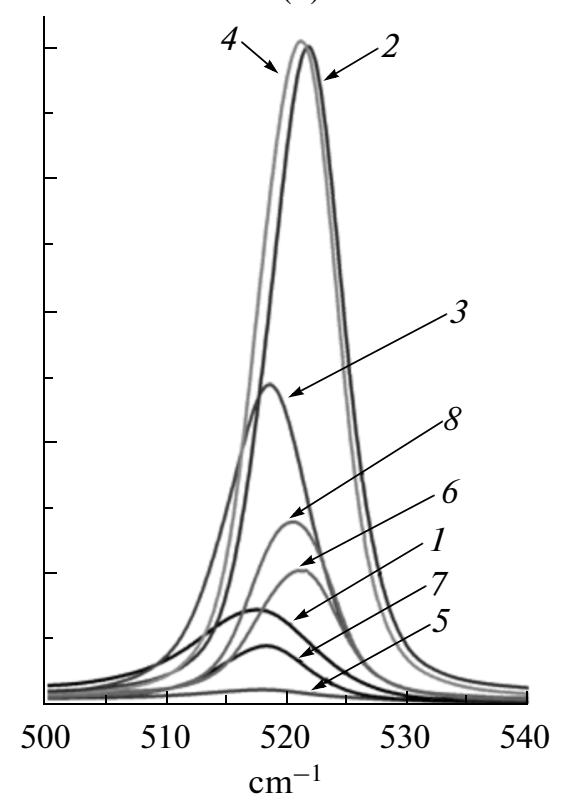

Fig. 3. RS spectra of the $\mathrm{SiO}_{2}(40 \mathrm{~nm}) / \mathrm{Si}$ (curves $1,3,5$, and 7) and $\mathrm{SiO}_{2}(600 \mathrm{~nm}) / \mathrm{Si}$ (curves 2, 4, 6, and 8) samples implanted with As and In ions in the range of optical phonons of (a) crystalline InAs and (b) crystalline Si: $(1,2)$ as-implanted samples; samples after annealing at $900^{\circ} \mathrm{C}$ for (3) 45 or (4) $30 \mathrm{~min}$; $(5,6)$ as-implanted samples irradiated with Xe; (7) samples after annealing at $900^{\circ} \mathrm{C}$ for 45 min and Xe irradiation; (8) samples after annealing at $900^{\circ} \mathrm{C}$ for $30 \mathrm{~min}$ and Xe irradiation.

$(40 \mathrm{~nm}) / \mathrm{Si}$ sample. The difference between the positions of the maxima can be explained if the InAs nanocrystals formed in the implantation of As and In ions into $\mathrm{SiO}_{2}$ are larger than those formed by implanting As and In into Si. However, the TEM data show that InAs nanocrystals incorporated into silica are smaller both before and after thermal treatment. It is known that the shift of the TO and LO phonon bands of InAs toward higher frequencies might be associated with mechanical stresses [10]. We may therefore assume that such a shift was in our case related to the presence of mechanical compression stresses affecting the InAs nanocrystals in the silica matrix.

The signal from InAs nanocrystals in all samples did vanish after they were irradiated with xenon ions (not shown). This suggests that nanocrystals could be amorphized upon irradiation with fast ions. However, high-resolution TEM shows that most InAs clusters remained crystalline after irradiation with Xe. The disappearance of the RS signal from InAs nanocrystals was therefore probably due to the formation of radiation defects in $\mathrm{Si}$ and $\mathrm{SiO}_{2}$ after ion irradiation. It is obvious that the structural changes occurring in the implanted layer affected the signal from the silicon substrate.

Irradiation with Xe ions sharply reduced the intensity of the band at $520 \mathrm{~cm}^{-1}$, associated with scattering from crystalline silicon, in all samples. The drop in the intensity of this band in the implanted $\mathrm{SiO}_{2}$ $(40 \mathrm{~nm}) / \mathrm{Si}$ sample indicates that a large number of radiation defects formed in silicon beneath the $\mathrm{SiO}_{2}$ layer. In the case of the implanted $\mathrm{SiO}_{2}(600 \mathrm{~nm}) / \mathrm{Si}$ sample, the band at $520 \mathrm{~cm}^{-1}$ is associated with scattering from the silicon substrate. The reduction in the intensity of this band due to irradiation with Xe ions was probably also related to the formation of radiation defects in the silicon substrate, since the range of fast xenon ions is on the order of several tens of micrometers. In addition, radiation defects can also form in a silica layer. This suppresses the $\mathrm{SiO}_{2}$ layer transmission and results in a corresponding weakening of the signal from the substrate.

\section{CONCLUSIONS}

Irradiation of a $\mathrm{SiO}_{2}(600 \mathrm{~nm}) / \mathrm{Si}$ structure with InAs nanoclusters in the oxide layer by fast $\mathrm{Xe}$ ions $\left(167 \mathrm{MeV}, 3 \times 10^{14} \mathrm{~cm}^{-2}\right)$ resulted in the ordering of nanoclusters along the direction of the ion beam. The round shape of larger precipitates became oval with major axes perpendicular to the surfaces of samples. The size of nanoclusters did not exceed the diameter (calculated using the thermal spike model) of the molten $\mathrm{SiO}_{2}$ region around the trajectories of Xe ions. The RS data showed that irradiation with Xe ions resulted in the amorphization of a certain fraction of InAs nanoclusters and the introduction of a large number of defects into crystalline clusters, damaging the surrounding $\mathrm{Si}$ and $\mathrm{SiO}_{2}$ matrices. 


\section{REFERENCES}

1. Komarov, F., Vlasukova, L., Milchanin, O., et al., Nucl. Instrum. Methods Phys. Res., Sect. B, 2008, vol. 266, p. 3557.

2. Komarov, F.F., Mil'chanin, O.V., Vlasukova, L.A., et al., Bull. Russ. Acad. Sci.: Phys., 2010, vol. 74, no. 2, p. 252.

3. Komarov, F., Vlasukova, L., Milchanin, O., et al., Mater. Sci. Eng. B, 2013, vol. 178, p. 1169.

4. Pruchnal, S., Facsko, S., Baumgart, C., et al., Nano Lett., 2011, vol. 11, p. 2814.

5. Leino, A.A., Djurabekova, F., and Nordlund, K., Eur. Phys. J., 2014, vol. 87, p. 242.
6. Vlasukova, L.A., Komarov, F.F., Yuvchenko, V.N., et al., Bull. Russ. Acad. Sci.: Phys., 2012, vol. 76, no. 5, p. 582.

7. Schmidt, B., Heinig, K.-H., Mucklich, A., et al., Nucl. Instrum. Methods Phys. Res., Sect. B, 2009, vol. 267, p. 1345.

8. Komarov, F.F., Phys.-Usp., 2003, vol. 173, no. 12, p. 1253.

9. Landolt-Börnstein: Numerical Data and Functional Relationships in Science and Technology, BerlinHeidelberg: Springer-Verlag, 1982, vol. 17a, p. 272.

10. Tenne, D.A., Milekhin, A.G., Bakarov, A.K., et al., Mater. Res. Soc. Symp. Proc., 2003, vol. 737, p. E13.8.1.

Translated by D. Safin 